second Report on Project DE-FG22-91PC91291

LOE/PC/91291--T1

Report on Progress as of January 31, 1991

DE92 011303

Previous Work

In our previous report, we described the design of glass reactors which allow us to carry out the reaction of coal model compounds with $\mathrm{H}_{2}$ or $\mathrm{D}_{2}$ at temperatures up to $450^{\circ} \mathrm{C}$ without contact of the organic reactants with metal surfaces. We indicated that we had carried out the thermolysis of 1,2-diphenylethane at $450^{\circ} \mathrm{C}$ and had found hydrogen replacement by deuterium to comparable extents in both the aliphatic and aromatic positions of starting materials and products. We are now prepared to give more detail concerning the results of these experiments.

\title{
New Data
}

The thermolysis of 1,2-diphenylethane in the presence of ca. 2000 p. s. $i$. of $D_{2}$ gas at $450^{\circ} \mathrm{C}$ gave products reported earlier by Poutsma' for the reaction in the absence of $D_{2}$ : toluene, $1,2,3,4-$ tetraphenylbutane, benzene, ethylbenzene, stilbene, 1,1diphenylethane, phenanthrene and diphenylmethane. We also found what appeared to be diphenylpropane and trace amounts of other materials. Eor comparison, we carried out the reaction at the same pressure of $\mathrm{N}_{2}$ and found most of the same products except, as reported by vernon, ${ }^{2}$ greatly reduced relative amounts of stilbene, benzene and ethylbenzene. These initial results are shown in Table I. 
GC\MS Data on the reaction mixture obtained in the $D_{2}$ reaction showed the distributions of deuterium shown in Table II. The data suggest that deuterium introduction is taking place both at aliphatic positions and in the aromatic rings (note both $d_{1}$ and $d_{2}$ in benzene.) To assess the relative amounts of aromatic and aliphatic substitution, the reaction mixture was subjected to gas chromatographic separation and the individual components analyzed by both ${ }^{2} \mathrm{H}-\mathrm{NMR}$ and ${ }^{1} \mathrm{H}-\mathrm{NMR}$. Sample results are shown in Table III for the conditions described in Tables I and II.

\section{Conclusions}

The facts which seem fairly clear at this point are:

(1) Benzene and ethylbenzene are formed in a process which involves $D_{2}$.

(2) Formation of stilbene is inhibited by the presence of $D_{2}$.

(3) Deuterium is introduced into the aljphatic positions of all molecules. Because it is unlikely that there is significant conversion of toluene to diphenylethane, it seems necessary to assume that deuterium is incorporated at the aliphatic positions of diphenylethane prior to cleavage. It may be that additional deuterium is picked up in toluene as part of the cleavage process (4) More deuterium is incorporated at the $\mathrm{CH}_{3}$ group of ethylbenzene than at aliphatic positions in this as well as other molecules.

We feel we have a reasonable working model to explain these facts and other preliminary data, but we will wait for confirming experiments to present this in a report. One important piece of 
experimental information is that stilbene does not show comparable deuterium incorporation when it is subjected to these reaction conditions as a pure compound. The amount of $D$ incorporation increases when diphenylethane is added to pure stilbene. This shows that diphenylethane is a promoter for the substitution of hydrogen by deuterium.

\section{Work in Progress}

Work is going on now to check and extend the study of diphenylethane. We have preliminary data at lower conversions and are checking its precision. Three graduate students have joined the group and will start work on the project this spring. We are in the process of designing a problem for each. One of these which has a high priority is to deuterium label specific locations in diphenylethane to see whether there is significant transfer from position to position under the reaction conditions. This information is critical to int rppreting our results. We will also be considering other promoters in the hope of finding one which will work at lower temperature. 
Table I.

Product Distribution in the Thermolysis of Diphenylethane at $450^{\circ} \mathrm{C}$ for 30 Minutes

\begin{tabular}{|c|c|c|c|c|}
\hline & $\begin{aligned} \text { Mole } & \\
\text { Under } & D_{2}\end{aligned}$ & $\begin{array}{cc}\text { wt. } & \text { f } \\
\text { Under } & D_{2}\end{array}$ & $\begin{array}{cl}\text { Mole } & q \\
\text { Under } & \mathrm{N}_{2}\end{array}$ & $\begin{array}{c}\text { Wt } \\
\text { Under } \mathrm{N}_{2}\end{array}$ \\
\hline 1,2-Diphenylethane & 23.5 & 36.6 & 36.1 & 47.1 \\
\hline Toluene & 47.8 & 37.1 & 47.1 & 31.1 \\
\hline $\begin{array}{l}1,2,3-\text { Triphenyl- } \\
\text { propane }\end{array}$ & 0.6 & 1.8 & 0.7 & 1.8 \\
\hline Benzene & 14.1 & 9.3 & 0.9 & 0.5 \\
\hline Ethylbenzene & 8.6 & 7.7 & $<0.1$ & $<0.1$ \\
\hline 1,1-Diphenylethane & 1.5 & 2.3 & 0.9 & 1.2 \\
\hline stilbene & 1.3 & 1.9 & 12.2 & 15.8 \\
\hline Phenanthrene & 0.8 & 1.2 & $<0.3$ & $<0.5$ \\
\hline Tetraphenylbutane & 0.25 & 0.8 & $<0.1$ & $<0.1$ \\
\hline Diphenylpropane & 0.44 & 0.73 & -- & - \\
\hline Diphenylmethane & 0.36 & 0.52 & 1.4 & 1.7 \\
\hline
\end{tabular}


Table II

Deuterium Distribution in Products from Thermolysis of Diphenylethane at $450{ }^{\circ} \mathrm{C}$ Under $D_{2}$

\begin{tabular}{|c|c|c|c|c|c|}
\hline Compounnd & $8 d_{0}$ & $f d_{1}$ & $f d_{2}$ & $8 \mathrm{~d}_{3}$ & $8 \mathrm{~d}_{4}$ \\
\hline $\begin{array}{l}\text { 1,2-Dipheny1- } \\
\text { ethane }\end{array}$ & 14 & 29 & 29 & 17 & 7 \\
\hline Toluene & 45 & 36 & 14 & 4 & \\
\hline Benzene & 46 & 41 & 12 & & \\
\hline Ethylbenzene & 18 & 34 & 29 & 14 & 4 \\
\hline $\begin{array}{l}\text { 1,1-Diphenyl- } \\
\text { ethane }\end{array}$ & 9 & 24 & 30 & 22 & 11 \\
\hline stilbene & 36 & 33 & 20 & 8 & 3 \\
\hline Phenanthrene & 25 & 34 & 25 & 12 & 4 \\
\hline $\begin{array}{l}\text { Diphenyl- } \\
\text { methane }\end{array}$ & 30 & 33 & 22 & 10 & 4 \\
\hline
\end{tabular}

Table III

Aliphatic vs. Aromatic Deuterium in Products from Thermolysis of 1,2-Diphenylethane under $D_{2}$ at $450^{\circ} \mathrm{C}$ for $30 \mathrm{~min}$.

Compounnd

Aromatic D

/molecule

\section{Aliphatic D /molecule}

$\mathrm{CH}_{2}$

$\mathrm{CH}_{3}$

1,2-Diphenylethane

0.91

0.65

Toluene

0.65

0.66

Benzene

0.50

0.28

0.6 


\section{References}

1. a. Poutsma, M. L.; Dyer, C. W. J. Org. Chem. 1982, 42, 4903. b. Buchanan, A. C.; Dunstan, T. S. J.; Douglas, E. C.; Poutsma, M. L. J. Am. Chem. Soc. $1986,108,7703$.

2. Vernon, L. W. Fuel $2980,59,102$. 

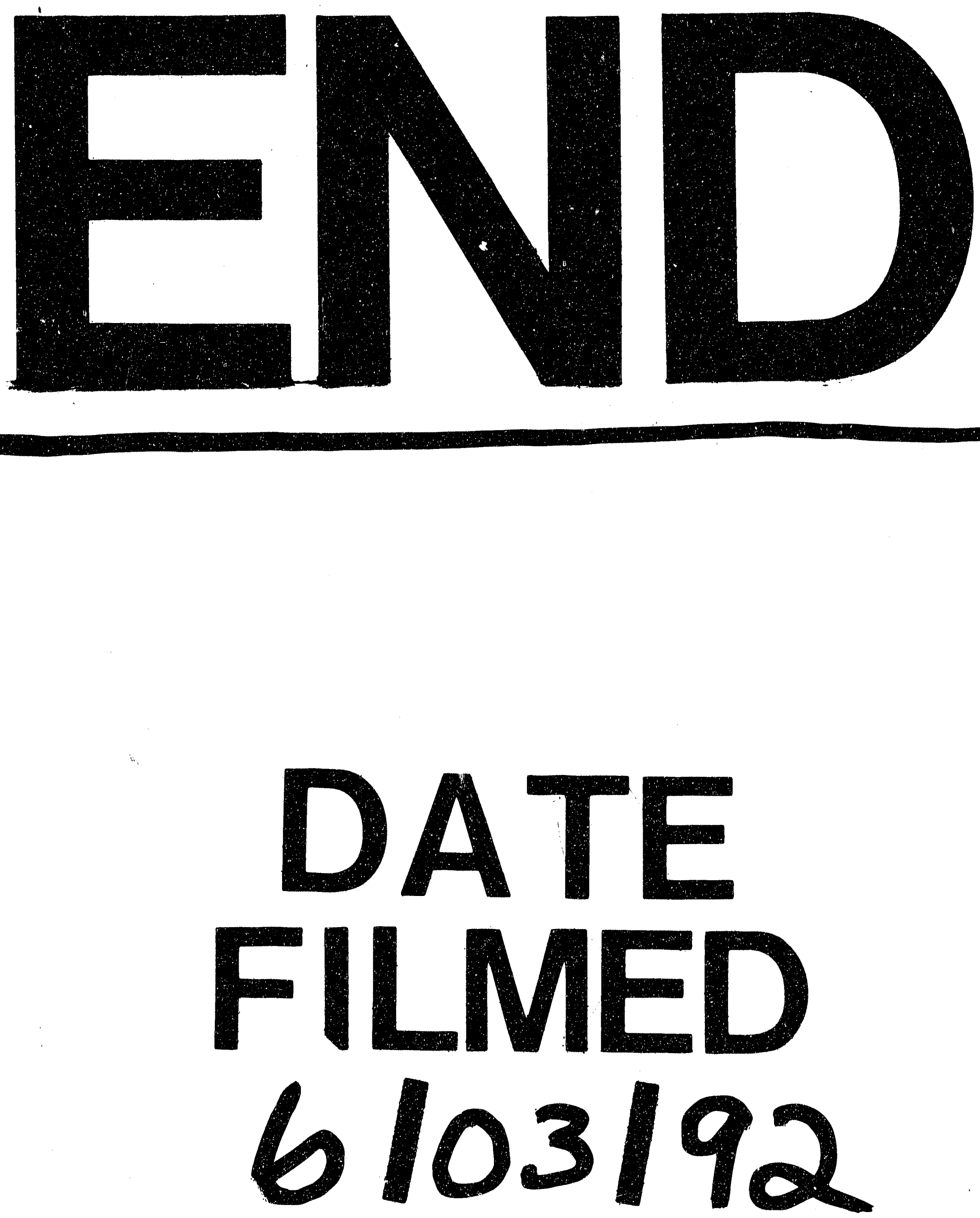
